\title{
CENTRAL BANK EXCHANGE RATE INTERVENTIONS AND MARKET EXPECTATIONS: THE CASE OF MEXICO DURING THE FINANCIAL CRISIS 2008-2009 Guillermo Benavides*
}

Banco de México

(Received April 17, 2011, accepted July 7, 2011)

\begin{abstract}
The objective of this paper is to examine if the exchange-rate interventions of the Central Bank of Mexico during the 2008-2009 financial crisis had an effect on the (Mexican Peso-US Dollar) exchange rate market expectations. Expectations are generated by Risk-Neutral Densities (RNDs) extracted from option prices; the used method to estimate RNDs is the volatility function technique proposed by Malz (1997). The obtained results show that interventions caused changes in expectations around the date of the intervention. There is a pattern of a statistically significant decreasing of the mean and variance in the implied exchange rate immediately after the period of intervention. The higher implied moments decrease as well. Finally, it was also found a causality effect that runs in both directions; between exchange-rate expectations and Central Bank interventions.
\end{abstract}

\section{Resumen}

El objetivo de esta investigación consiste en examinar si las intervenciones en el tipo de cambio por el Banco Central de México durante el período de la crisis financiera de 2008-2009 influyeron en el tipo de cambio (peso mexicano-dólar estadounidense) a precios de mercado. Las expectativas se generan mediante una Densidad de Riesgo-Neutral (DNR) obtenida de los precios de opciones; el método utilizado para estimar la DNR es la técnica de la función de la volatilidad propuesta por Malz (1997). Los resultados obtenidos muestran que las intervenciones causaron cambios en las expectativas en torno a la fecha de la intervención. Así mismo, se detecta un patrón en la disminución, estadísticamente significativa, de la media y la varianza en el tipo de cambio implícito inmediatamente después del período de intervención. Los momentos implícitos de orden superior también disminuyen. Por último se encontró un efecto de causalidad que funciona en ambas direcciones; entre las expectativas de tipos de cambio y las intervenciones del Banco Central.

JEL Classification: C14, E44, E58, F31

Keywords: Exchange Rate Interventions, Market Expectations, Mexican Peso - U.S. Dollar Exchange Rate, Risk-Neutral Densities, Volatility Function Technique.

* Banco de México. Av. 5 de Mayo 2, Centro, México, D. F., CP. 06059, México. Tel. (+52)55-5237-2000, Ext.3877. Fax (+52)5237-2687. Email: gbenavides@banxico.org.mx

I thank Ana Luisa Mexicano and Luis Mejía for excellent research assistance. The opinions in this paper correspond to the author and do not necessarily reflect the point of view of Banco de México. The author acknowledges financial support from CONACYT (especially Sistema Nacional de Investigadores).

The author is very grateful to the anonymous referees for their comments. 


\section{Introduction}

Risk-Neutral Density (RND) estimation is of fundamental interest in several financial applications. For instance, RNDs are widely used for measuring the unobserved market expectations for several financial assets. Gauging market expectations could be useful for hedging, risk management, trading, policymaking, among others (Taylor, 2005). Given that a measure of market expectations give an idea of the market's reaction to certain policy events, RNDs are particularly useful to policy makers. Persons who take financial decisions often rely on the market's behavior to have an idea of the implications of certain economic policy events, like for example monetary policy actions by a Central Bank (Mc Manus 1999, Castrén 2005). Furthermore, many decisions are taken anticipating what could occur in the future, thus, a forecast of the volatility of financial variables extracted from RNDs is a relevant piece of information.

Even though the RND methodology literature is evolving through time there are basically three broad approaches used for estimating RNDs. These are parametric, constructing a model for the return process that will produce the RND and non-parametric approaches (Figlewski, 2009). Among the parametric models, there are models based on assuming a functional form for the RND and its parameters are estimated by minimizing the differential between observed and predicted prices of options e.g. mixture of lognormal (Rubinstein (1994), Bahra (1997) and Melick and Thomas (1997)). Or adding tails to the unknown distribution with a Generalized Extreme Value (GEV) function as it is proposed by Figlewski (2009). The RND can also be estimated by assuming for the underlying asset a particular stochastic process as it was postulated by Bates (1991), and Malz (1996). Finally, there are non-parametric methods like the one postulated by Malz (1997) in which an interpolation of exercises prices was derived in order to recover a RND from option prices. ${ }^{1}$ Even though several models are widely used by academics and practitioners to extract RNDs from options, nowadays there is no consensus about which method is superior in terms of accurate estimation. Taylor (2005) enumerates several desirable properties that a RND estimation should have. But some researchers will use a specific estimation method based on data availability, consistent estimation, among others. A method we believe is consistent is the Volatility Function Technique (VFT) postulated by Malz (1997) and is the method applied here. The VFT was especially design for extracting RNDs for exchange rates. For a complete application of the method it is necessary to have hard data on implied volatility data. This is usually only available for exchange rate options. We give a brief description of the method in a subsequent section.

In this research paper an event study analysis of the dynamics of exchange rate market expectations is carried out when there are Central Bank interventions. Specifically, we analyze the Mexican Central Bank (Banco de México) exchange rate interventions during 2008-2009 financial crises. We propose to test the following null hypothesis $\mathrm{H}_{0}$ : Banco de México interventions did not affect agent's expectations about the Mexican peso-USD exchange rate. In order

\footnotetext{
1 This non parametric method is applied for exchange rates. This is because it requires hard data on implied volatilities. As it is known over-the-counter option market investors often trade with implied volatilities. This is why there is hard data available of implied volatilities.
} 
to test the previously mentioned null hypothesis estimations about expectations are carried out. The measurement of exchange rate expectations are carried out applying VFT to obtain RNDs ${ }^{2}$. The same type of methodology is also applied in the research paper from Abarca, Benavides ad Rangel (2010), but here the focus is in foreign currency interventions, whilst in the former, the focus is in monetary policy announcements events (interest rate announcements made by the Mexican Central Bank ). Even though in both research papers the same methodology to extract RNDs is used the research questions for both are different. In the present research document the procedures applies relevant financial data for the Mexican Peso-US Dollar exchange rate. We analyze the RNDs and analyze their dynamics around the dates Banco de México intervened in the foreign exchange market. These events occurred during the financial crisis that hit the Mexican exchange rate market (Mexican peso-USD) mostly during the last quarter 2008 and first semester 2009. Following a similar approach to that one performed by Galati and Melick (2002) we apply Granger Causality and other similar tests for statistical relationships between interventions and exchange rate market expectations. Again, these RNDs are taken as proxies of exchange rate expectations. Lastly, we conduct an econometric test to capture any causality interventions and foreign exchange expectations. Robustness checks for the results are carried out using intraday data.

In terms of the direct (extraordinary) interventions made by Banco de Mé xico during October 2008, it can be observed that once the Mexican Central Bank intervened there were statistical significant decreases in the exchange rate market expectations extracted from RNDs (implied means). For the second moment we observe on average a systematic decrease in the implied standard deviation after an intervention event. There are also statistical significant decreases for higher moments of the implied distributions i.e. implied skewness and kurtosis. The Granger Causality tests confirm a two-fold relationship between market expectations and Central Bank interventions that is in line with other studies in the literature (Dominguez and Frankel (1993), Fatum (2000), Galati and Melick (2002)). To the best of our knowledge, this type of research has never been done for the Mexican peso-USD exchange rate.

The layout of this paper is as follows. Section 2 gives a brief literature review and discusses the methodology used to obtain the RNDs. The data and our proxies for ex-post realized volatility are presented in Section 3. Section 4 presents the empirical results and an analysis of them. Finally, Section 5 concludes.

\section{Literature Review and Methodology}

\subsection{Exchange Rate Interventions by Central Banks}

We define interventions as those exchange rate transactions that monetary authorities carry out with the objective of influence the exchange rate (Neely: 2001). Even though there exist indirect types of interventions (non-announced

\footnotetext{
2 Estimation of RNDs using VFT method for the case of the Mexican peso- US dollar exchange rate, can be found in Benavides and Mora (2008) and Díaz de León and Casanova (2003).
} 
interventions conducted by the Central bank usually through financial institutions) for this research paper we focus in direct interventions. The latter is the one that it is publicly announced. Usually occurs unilaterally through foreign currency auctions made by one of the relevant Central Banks. But there are also coordinated direct interventions for which, both of the relevant central banks intervene in a coordinated matter. These both type of interventions have a direct influence on the exchange rate market (Dominguez and Frankel (1993)). The reasons to intervene in a foreign exchange market vary. Sometimes is to provide liquidity or simply to reduce apparent exchange rate disequilibrium. ${ }^{3}$ In this research paper we consider only unilateral interventions carried out by Banco de México (Mexico's Central Bank). We consider these types of interventions because during the global financial turmoil in 2008-2009, Banco de México intervened unilaterally in order to influence the Mexican peso-USD exchange rate through foreign currency auctions (that is without a direct intervention by the FED). These types of auctions in Mexico are also known as extraordinary auctions.

Nowadays there is a large literature about analyzing foreign exchange interventions. However, up to date there is no consensus about the effectiveness of these types of interventions. If the effectiveness is measure as the degree of influence that the intervention had on the exchange rate there are still mix conclusions in the academic literature. For example, there are some studies that mention that interventions do affect the exchange rate level including the agent's expectations (Dominguez and Frankel: 1993, Lewis: 1995, Galati and Melick (2002). Other part of the literature shows that interventions are not effective. For example, Baillie and Osterberg (1997) documented that using a time-dependent conditional heteroskedasticity martingale model, the FED interventions from August, 1985 to March, 1990 did not influence the mark/dollar or yen/dollar exchange rates even though the objectives were to influence those exchange rates. Several research papers have shown that the application of GARCH models suggest a statistical significant relationship between FX interventions and exchange rate volatility (Connolly and Taylor: 1994). Finally, there are some studies that relate the intervention as a "success" according to the time period analyzed (Galati and Melick: 2002). ${ }^{4}$

There are relatively fewer research papers that have documented the relationship between FX interventions and exchange rate market expectations. We define as exchange rate market expectation the economic factors that agents may consider relevant to change their beliefs about future exchange rate quotations (Deutsche Bundesbank Monthly Report October 2001). For this project we consider expectations as the "pulse" in the market for the exchange rate Mexican peso-USD. Several research documents have shown that interventions carried out by central banks, indeed, had influenced exchange rate market expectations. Some recent papers are Lyons (1997) and Galati and Melick (2002).

\footnotetext{
3 For a more detailed explanation (and a comprehensive survey) of the motivations to intervene in a foreign exchange market the interested reader can refer to Edison (1993).

4 Galati and Melick (2002) proposed four contemporary intervention periods. These are: the period of the Plaza Accord 1985; the period around the Louvre Accord 1986-88; the period were central banks tried moderating excessive fluctuation of the dollar 1988-92; and finally, the period of support of the dollar 1992-96.
} 
The former shows within a microstructure framework that exchange rate traders can be informed and uniformed at a specific point in time. The interaction between these types of informed and uninformed traders allows exchange rate dynamics to be influenced by official foreign exchange market interventions. The latter, Galati and Melick (2002) work show that using RNDs it is possible to quantify the statistical relationship between interventions and expectations. The present research paper has the aim to add information to the academic literature about how FX interventions influence exchange rate market expectations. The contribution is basically that the empirical study is conducted for the Mexican peso-USD during a recent period of high exchange rate volatility due to the international financial crisis of 2008-2009. Since RNDs are used to gauge market expectations this present research paper extends the work made by Galati and Melick (2002). A difference between the present paper and theirs is that here RNDs are estimated using a novel methodology proposed by Malz (1997) that is only applied for exchange rates. On the other hand, they used a method known as mixture of lognormal, which is fundamentally different. While their method is a parametric one the one applied here proposed by Malz (1997) is non-parametric. Finally, the work in their paper considers Mark/USD and Yen/USD exchange rates whilst in the present paper the Mexican Peso-USD exchange rate is analyzed.

\subsection{Risk-Neutral Densities Definition}

The idea to estimate RNDs implied by option prices was first postulated by Breeden and Litzenberger (1978). The main reason to do this was the belief that derivative markets provided a rich source of forward-looking financial information embedded in them. A way to extract this information is by estimating an implicit probability distribution from option prices, which were traded in financial markets for a specific underlying asset. That is, the underlying assets' distribution implied by the observed market prices of those options. Given that the models used to estimate these probabilities have the assumption that the agents are risk-neutral, the resulting probability density is called risk-neutral density. The relevant RND is a probability distribution of the underlying asset price for the date the options expire.

In a detailed option-pricing model derivation Breeden and Litzenberger (1978) proved that the RND that it is contained in option prices can be extracted by calculating the second partial derivative of the call price function $c(X, T)$, with respect to the different exercise prices $(X)$ and with maturity at $(T):$

$$
\begin{gathered}
c(X, T)=\int_{X}^{\infty} e^{-r T}\left(S_{T}-X\right) f\left(S_{T}\right) \mathrm{d} S_{T} \\
\frac{\partial^{2} c(X, T)}{\partial X^{2}}=e^{-r T} f(X) .
\end{gathered}
$$

Rearranging then it is possible to have the following definition,

$$
f(X)=e^{r T}\left(\frac{\partial^{2} c(X, T)}{\partial X^{2}}\right)
$$


where $f\left(S_{T}\right)$ represents the risk-neutral probability function (RND) of the underlying asset (spot prices at maturity of the option), and $r$ is the domestic risk-free interest rate. The problem with this definition is the assumption that the call price function is continuous for the range of exercise prices. As it is known this is not realistic given that in practice only some prices in discrete time are available or observed. Considering this limitation Shimko (1993) proposed an interpolation method using the exercise prices available. In subsequent research, Malz (1997b) proposed to interpolate across implied volatilities (obtained with a GK model) and the delta. In this case, the delta has to pass through at least three points on the volatility smile as it will be explained in more detail below in Section 2.2.1.

RNDs estimations do not only give a point estimate forecast about a specific underlying asset but they give the whole distribution expected by the market around a point estimate forecast. Again, these probability densities are for the date the options expire, therefore all the options used must expire on the same date. Extracting a RND provides information about market sentiment. For example, if an exchange rate shows RNDs with skewness that is systematically positive through time, the interpretation is that the market is expecting one of the currencies to depreciate (or keep depreciating) in the near future.

Even though substantial amount of research has been done about this topic, there still is a current debate in the literature about how different are the riskneutral probability distributions compared with the market's "true" probability distributions. For the case of exchange rates Christoffersen and Mazzotta (2004) found that RNDs provide reliable estimates of true density functions. The evidence was corroborated for stock indices (Liu, et.al. 2007).

Considering the actual evidence it could be assumed that from a theoretical viewpoint, RNDs are a parsimonious and reliable method for capturing the market's belief about a future asset price distribution. However, the research question about the differences between RNDs and "true" probability distributions (real-world densities) is not analyzed here.

\subsubsection{The Volatility Function Technique}

In the early 1990s Shimko (1993) proposed an idea to recover a RND from an interpolation of option prices. The intuition behind Shimko's method was motivated by the fact that usually there is not enough option exercise prices spread out evenly enough to obtain the necessary information to recover the whole RND. In over-the-counter currency option markets most of the exercise prices are concentrated around the at-the-money exercise price. Therefore, Shimko proposed a parabolic function to estimate a curve for the implied volatility function vis-à-vis exercise prices i.e. the smile curve considering that there are relatively few traded exercises prices. Once the 'smoothed' smile implied volatility function is estimated it is possible to generate a smooth call option prices curve using the Black-Scholes equation (BS). From these interpolations it was then relatively easy to extract the RND. The volatility function technique (VFT) was originally postulated by Malz (1997) and he extended the idea proposed by Shimko (1993), in which an interpolation of exercises prices was derived in order to recover a RND from option prices. The extension is basically that Malz uses option strategies' implied volatility data, which is com- 
monly observed in currency options in order to do the interpolation procedure and then extract the RND.

The VFT has been applied in several studies in the literature. Among those studies Bliss and Panigirtzoglou (2000) extracted RNDs for the FTSE-100 stock index and short sterling futures. They concluded in favor of the VFT after a statistical comparison with several RND estimation methods arguing that the VFT had higher goodness-of-fit and stability of the parameters. On the other hand, Mc Manus (1999) documented that the VFT was not as accurate as the mixture of lognormal method. The former was relatively stable but the latter had higher goodness-of-fit for the parameters for the case of Eurodollar options. Also for currency options Micu (2004) extracted RNDs for twelve emerging markets currencies vis-à-vis the US Dollar. He applied the VFT method and concluded that there is a trade-off between goodness-of-fit accuracy and stability of the parameters, which means that in order to have more stable parameters there is some loss in accuracy (goodness-of-fit).

In order to understand the VFT methodology it is important to star analyzing the equivalent BS model for exchange rates was postulated by Garman and Kohlhagen (1983: henceforth, GK). The underlying assumptions of an option valuation model for exchange rates are the following: 1) interest rates are non-stochastic, 2) there are no arbitrage profits, 3) all options are Europeanstyle, 4) agents are risk-neutral, 5) there are no transaction costs or taxes; and, 6) the price for the underlying asset follows a Geometric Brownian Motion. While some of these assumptions will be quite strong there is still interest to estimate RNDs. This is because by estimating them there is useful information about market expectations, specially around an economic event, that could give us some feedback about the dynamics of a specific financial asset regardless of the possible unrealistic assumption of a risk-neutral world. ${ }^{5}$

To calculate the implied RND of an asset we need an option valuation model together with the inputs for that model. The inputs for a typical currency option valuation model are the domestic risk-free interest rate, $r$, foreign riskfree interest rate, $r_{f}$, time to maturity, $T$, spot price of the underlying asset, $S$, the exercise price, $X$, and the market price of the option. For the present study, the GK option pricing model is used. This is a model derived from the Black-Scholes formula and it is commonly used in the literature to price currency options. The GK model is:

$$
\begin{gathered}
c(X, T)=S e^{-r_{f} T} N\left(\mathrm{~d}_{1}\right)-X e^{-r T} N\left(\mathrm{~d}_{2}\right), \\
p(X, T)=X e^{-r T} N\left(-\mathrm{d}_{2}\right)-S e^{-r_{f} T} N\left(-\mathrm{d}_{1}\right) \\
d_{1}=\frac{\ln \left(\frac{S}{X}\right)+\left(r-r_{f}+\frac{1}{2} \sigma^{2}\right) T}{\sigma \sqrt{T}}, \\
d_{2}=d_{1}-\sigma \sqrt{T},
\end{gathered}
$$

,

\footnotetext{
5 There is the possibility for certain RND estimation methods to transform the estimated risk-neutral density to a real-world density. The latter relaxes the assumption of a risk-neutral world (See Liu, et.al. 2007).
} 
where $c$ is the value of the European-style call option, $p$ is the value of the European-style put option, and $N(x)$ is the cumulative probability distribution function, which is Gaussian. $\sigma^{2}$ is the annualized price-return variance. For each trading day, these implied RNDs are derived from nearby to expiration over-the-counter one month option contracts for the MXN-USD exchange rate.

If observed option prices in the market are used instead of theoretical ones it is possible to implicitly extract the probability distribution that the agents had when they traded the options. Supposing that the $c, p, S, X, r, r f$, $T$ in Equation 4 above is observed. After making an assumption about $\sigma$ the RND can be implicitly estimated by finding the risk-neutral probability function $f(X)$ in terms of spot prices at the maturity of the option $\left(S_{T}\right)$, relevant to that specific traded option premium. So, instead of assuming a standard $N(x)$ as it is shown in Equation 4 above, the RND is implicitly extracted from the model using the observed variables.

With the estimated call prices the RND can be extracted by applying the Breeden and Litzenberger approach (explained in the previous Section above). The main difference with Malz is that the latter does not use a parabolic function to estimate the smile curve but instead he applies implied volatilities from option pricing strategies (risk reversals and strangles). ${ }^{6}$ The objective is to estimate a curve matching implied volatility vis-à-vis the delta and then calculate the call option prices from it by using BS. Malz argued that his method is more accurate for modeling financial data given that option strategies' implied volatilities, like risk reversals $(r r)$ and strangles $(s t r)$, capture the market's expectations for the relative likelihood of exchange rate depreciations (implied skewness) and extreme events (excess implied kurtosis).

Malz (1997) shows that a RND can be estimated by interpolating the smile curve. Interpolation can be carried out in terms of the implied volatilities determined from market expectations. The implied volatilities considered are: at-the-money where the forward price $(F)$ is equals to the exercise price $(\mathrm{atm})$; risk reversal; and, strangle. For exchange rates these were taken from market traders. The implied volatilities from the above mentioned option strategies for a 25 delta call and put option can be theoretically obtained as follows.

The $r r$ and the str can be expressed as,

$$
\begin{gathered}
r r_{t}^{25 \triangle}=\sigma_{t}^{\left(\triangle_{0.25}^{c}\right)}-\sigma_{t}^{\left(\triangle_{0.25}^{p}\right)}, \\
s t r_{t}^{25 \triangle}=0.5\left[\sigma_{t}^{\left(\triangle_{0.25}^{c}\right)}+\sigma_{t}^{\left(\triangle_{0.25}^{p}\right)}\right]-\sigma_{t}^{A T M} .
\end{gathered}
$$

Incorporating the volatilities to a quadratic function, it is then possible to obtain the following smile curve (Malz: 1997),

\footnotetext{
6 A risk reversal is an option trading strategy that it is constructed with an out-of-themoney (OTM) long position of a call option and an OTM short position of a put option both with the same time to expiration (the investor is hoping for extreme increases in the exchange rate to make a profit). A strangle is another option trading strategy, which consists in an OTM long position of a call option and an OTM long position of put option both with the same time to expiration (the investor is hoping for extreme movements in either direction of the exchange rate to make a profit).
} 


$$
\sigma(\delta)=a t m-2 r r(\delta-0.5)+16 s t r(\delta-0.5)^{2}
$$

where $\sigma($.$) represents the market's implied volatility as a function of delta (\delta){ }^{7}$ Equation 8 is tansformed in order to express the implied volatility in terms of exercise price $(X)$ and not in terms of the delta. Thus, the following is the definition of the delta function :

$$
\delta=e^{-r f T} * N\left(\frac{\ln \left(\frac{F_{t}}{X}\right)+\left(\frac{\sigma^{2}}{2}\right) T}{\sigma \sqrt{T}}\right)
$$

where the notation is as defined previously. Equation 9 is substituted into Equation 8 and then Equation 10 below is obtained,

$$
\sigma(\delta)=a t m-2 r r\left(e^{-r f T} * a_{1}-0.5\right)+16 s t r\left(e^{-r f T} * a_{1}-0.5\right)^{2}
$$

where $a_{1}$ is equal to $N\left(\frac{\ln \left(\frac{F_{t}}{x}\right)+\left(\frac{\sigma^{2}}{2}\right) T}{\sigma \sqrt{T}}\right)$. In order to extract the RND $f\left(S_{T}\right)$ form option prices for the underlying asset the Breeden and Litzenberger (1978) result is applied here. Substituting the above mentioned into Equation 3, it is possible to estimate the probability density function for the underlying asset, as follows:

$$
f\left(S_{T}\right)=e^{r T}\left[F\left(b_{1}+n\left(d_{1}\right) d_{1}\left(\frac{1}{X_{v} \sqrt{T}}\right)^{2}\right)-X\left(b_{2}+n\left(d_{2}\right) d_{2}\left(\frac{1}{X_{v} \sqrt{T}}\right)^{2}\right)\right]
$$

where $b_{1}$ is equal to $\left(\frac{n\left(d_{1}\right)}{X^{2} v \sqrt{T}}\right)$, and $b_{2}$ is $\left(\frac{n\left(d_{2}\right)}{X^{2} v \sqrt{T}}\right)$,

$$
\begin{aligned}
& d_{1}=\frac{\ln \left(\frac{F_{t}}{X}\right)+\left(\frac{v^{2}}{2}\right) T}{v \sqrt{T}}, \\
& d_{2}=\frac{\ln \left(\frac{F_{t}}{X}\right)-\left(\frac{v^{2}}{2}\right) T}{v \sqrt{T}},
\end{aligned}
$$

$n(x)$ is the normal density function and $v$ represents the option implied volatility $(\sigma)$, which makes the left hand side equals to the right hand side in Equation 10. Using different values of $X$ sufficiently spread out across the whole possible range of option exercise prices it is then possible to extract the RND using the observed option prices.

\footnotetext{
7 The $\delta$ is defined as the sensitivity of the option price to a change in the spot price.
} 


\section{Data}

The data for the exchange rate consists of daily spot and futures quotes obtained from a Banco de México's financial database ("SIE") and the Mexican Derivatives Exchange (MexDer) respectively. ${ }^{8}$

The daily data for the spot exchange rate Mexican Peso-USD consists of daily averages of quotes offered by major Mexican banks and other financial intermediaries (also published in the Mexican Official Gazette i.e. "Diario Oficial de la Federación"). The futures exchange rate prices considered are quotes of the near-by-expiration traded contracts at MexDer. The exchange rate atm, rr, and str implied volatilities were obtained from Switzerland-based UBS Financial Institution data base. ${ }^{9}$ The sample period under analysis is from February 5th, 2008 to March 2nd, 2009. The final selected sample size consists of 217 daily observations for the exchange rates. The data needed to estimate RNDs also consists of the domestic discount rate, which is the daily 28-day secondary market interest rates of Mexican Certificates of Deposit (CDs) obtained from the same source, and US CDs obtained from the Federal Reserve (FED) web page with the same maturity in order to include the equivalent foreign risk-free discount rate in the estimations. For the Granger causality regressions data about the amount of USD auctioned was needed. These data was obtained from Banco de México and is available in its webpage (extraordinary auctions link). The intraday data for robustness checks are realizations of the Mexican peso-USD exchange rate with a frequency of 5 minutes. The transactions were carried out through the Reuters electronic platform. The exact reference is Reuters Matching (RIC: MXN=D2). We considered transactions from 10:00 GMT until 23:00 GMT. This interval was chosen given that almost 95 percent of the transactions fall within this range. The observations are taken at each 5 -minute interval or the last observation if there is no observation at the exact time interval. The intraday data is only for the 8th, October, 2008.

\section{Empirical Results}

The volatility of the Mexican Peso-USD exchange rate was relatively high during the months of the 2008-2009 financial crisis. Figure 1 shows the volatility obtained with a GARCH $(1,1)$ model for the period February 5th, 2008 to March 2nd, 2009. i.e. the time period under analysis. It can be observed in Figure 1 the significant increase in volatility in October, 2008. It was one of the worst Mexican Peso exchange rate depreciations in many years. On 5th August, 2008 the closing exchange rate was Mexican 9.92 pesos per USD. During the crisis on 2nd March, 2009 the exchange rate reached a level of 15.37 Mexican pesos per USD, that is, nearly a $55 \%$ depreciation of the Mexican currency in a few months. However, most of the high volatility occurred during October 2008 (see Figure 1). It is believed that the large volatility observed during

\footnotetext{
8 Banco de México's is Mexico's Central Bank, with web page:http://www.banxico.org.mx

9 The implied volatility data are taken from quotes made on volatility trading and not over option prices. In other words, it is hard data for volatility. It is common practice among option traders to trade with volatility quotes in exchange rate option markets (See Cooper and Talbot (1999) for more details). These quotes are used for the interpolation procedure (Malz: 1997) explained above.
} 
this month motivated Banco de México to intervene in the Mexican Peso-USD exchange rate market. The reason as it was stated by the Mexican Exchange Rate Commission was to provide liquidity to the market (or could be thought as basically to prevent the Mexican Peso to fall to historical low levels). ${ }^{10}$

Figure 1. Mexican Peso-USD Exchange Rate Daily Volatility.

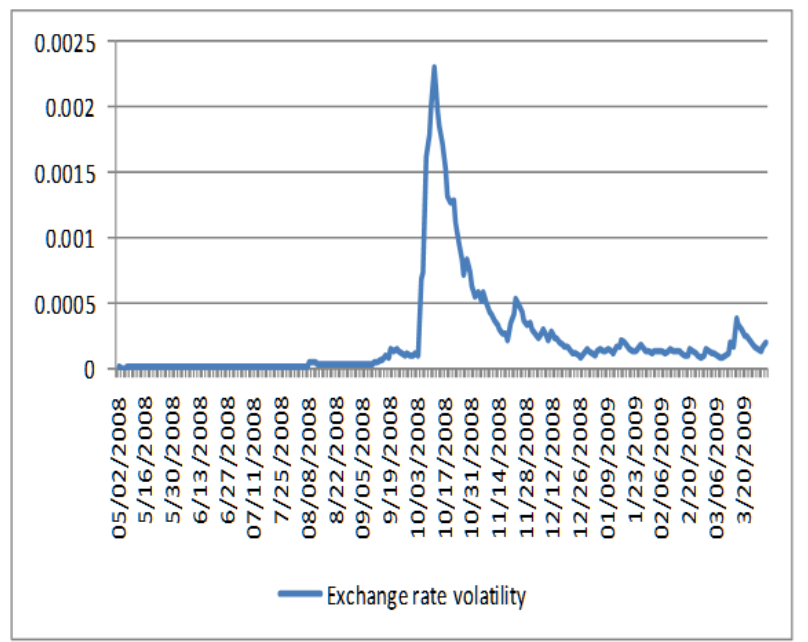

Considering the high volatility observed in October, 2008 Banco de México conducted a direct non-coordinated intervention, that is, that it did it itself without the intervention of the FED. The days of these direct Interventions were the following: 8, 9, 10, 16 and 23rd, October 2008. These Interventions are also known as extraordinary auctions to buy Mexican pesos (subsalts extraordinarias). It was a period of relatively high turbulence in financial markets; however, the only relevant macroeconomic announcements around those days for the Mexican economy were basically those of the Banco de México interventions. In other words, there were no major monetary policy announcements by either country on those days Banco de México intervened. Considering the RNDs estimations using the methodology presented in Section 2.2.1 above, Figures 2 - 4 show the RNDs for those days when the Central Bank of Mexico intervened in the exchange rate market (these are one-month ahead density predictions). In these figures a RND is shown for the day of intervention in addition to RNDs around the event days. Figure 2 shows the RND for the day before the intervention, 7th October, 2008. It also shows the RNDs for the days there were interventions close to that date i.e. 8, 9 and 10th October. It is clear to see that the RND estimated for the day before the intervention shows relatively less implied volatility compared with the others RNDs. This can be observed in the tails of the implied distribution. The RND for the day before the intervention has smaller tails compared to the others. As a matter of fact the uncertainty in the market was clearly increasing as time passed as we can observe that the

10 The interested reader can refer to the Exchange Rate Commission announcement, 8th October, 2008 (Comunicado de la Comisión de Cambios). Banco de México and SHCP. This is available at the Banco de Mexico Web page. 
tails of the implied distributions are getting larger for the days after the first intervention. The interpretation of this is that financial agents were still uncertain about their exchange rate expectations even though the Central Bank of Mexico had already intervened. This situation probably explains why Banco de México had to intervene for several days in October. Market expectations were uncertain. By looking at the implied skewness it is shown that these were getting larger (positive). That is, financial agents were expecting a larger depreciation of the Mexican Peso-USD exchange rate within a one-month time frame.

Figure 2. RNDs for the Day before and during the Intervention

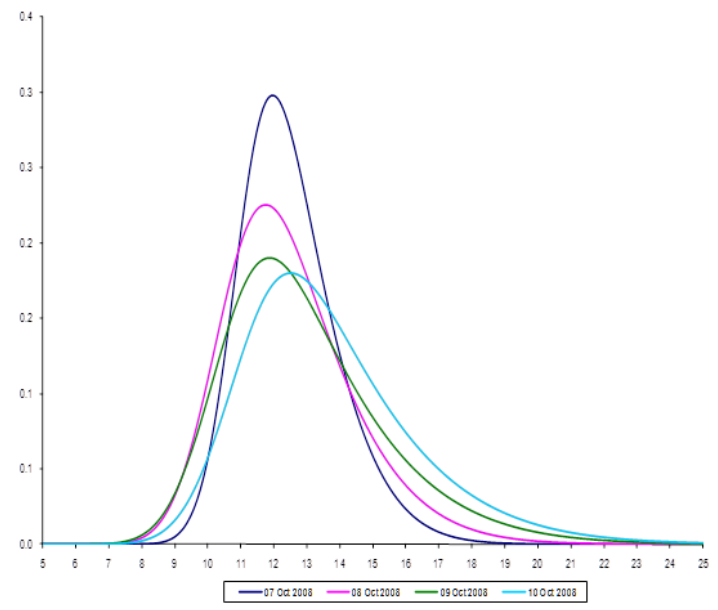

Figure 3 presents the RNDs for the day previous to the 16th, October intervention in addition to the RND for the day after that intervention (16th, October). Contrary to the previous graph, in Figure 3 it can be observed that the RNDs have fewer variations around those days. For the 15th, October, the RND has larger tails than the other implied densities. When the intervention occurred, the next day, the tails get smaller but only marginally. The RND estimated for 17th, October 2008 (the day after that intervention) shows a smaller right tail compared to the other tails. This can be explained by the possibility that market traders were now considering the interventions effective in terms of reducing the volatility observed in the market. This is shown by a smaller implied expected volatility one-month ahead following the intervention. It can also be observed that the implied mean decreases after that intervention as shown with the RND for the 17th, October shifting to the left. So apparently, the expectations about a higher USD in the future Mexican Peso-USD exchange rate decreased after the 16th, October interventions as shown in the implied density for 17th. The latter date has a smaller implied mean and implied standard deviation. Finally, Figure 4 shows the RNDs for the day before and after the last direct intervention in that month. The results are qualitatively similar to those for Figure 3. That is, the expectations about the future exchange rate 
level and volatility decreased after that last October intervention. This can be observed with the 24th, October RND, which has shifted to the left and has smaller tails than the other implied densities. These changes are marginal if compared with the first intervention episode earlier that month.

Figure 3. RNDs for the Day before, during after the Intervention

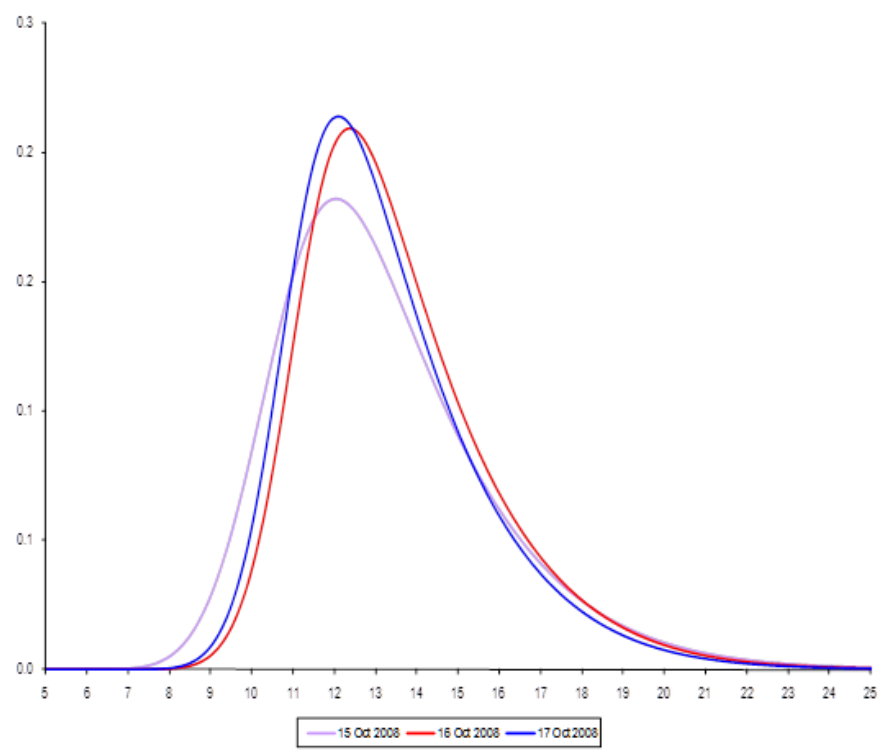

Figure 4. RNDs for the Day before, during and after the Intervention.

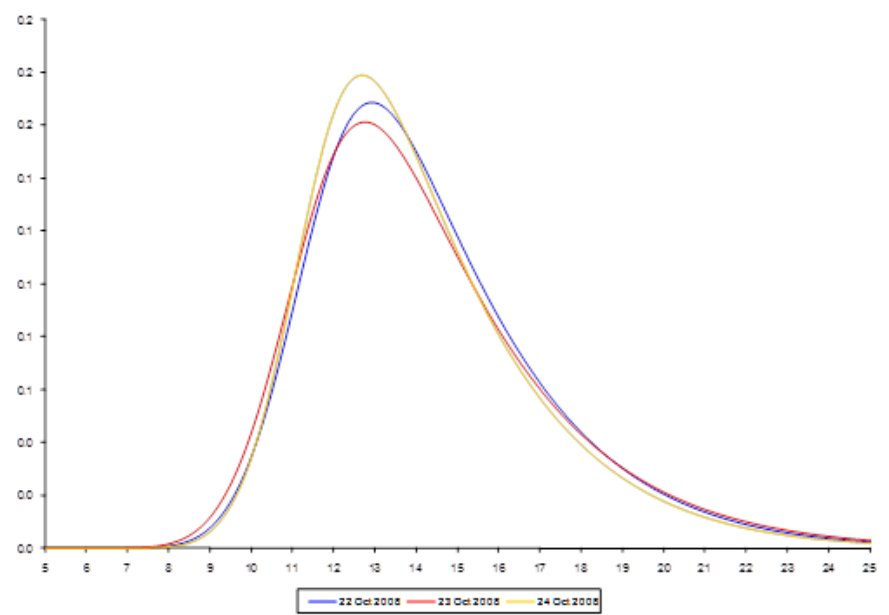


A similar qualitative result can also be observed in Figures 5-8. In these figures $X_{0}$ represents the day the extraordinary auction took place, whilst $X-i, X+i$ represents the day before or after, respectively, the extraordinary auction. Considering that there were interventions in three consecutive days there is a possibility of overlapping of information about the events. That is, it may be not possible to distinguish the impact of the specific intervention on the exchange rate expectations. For this reason, only the first day of the intervention is consider for that block of days i.e. 8, 9, 10 October 2008. So, only the intervention that occurred on the 8th, October is included in this analysis. Since there were several intervention episodes after the 8th, October the $X_{s}$ values refer to the mean value of those episodes. For example, $X_{0}$ refers to the average value for the dates 8, 16 and 23rd, October 2008, which were the days the interventions took place. The same logic applies for the days before and after the intervention day i.e. these are average values.

Statistical test were conducted to test for statistical significant differences in the implied means and variances through time. Most of the tests reject the null of equality of the means and variances at the $95 \%$ significance level. ${ }^{11} \mathrm{In}$ other words, the first and second moments are statistically significantly different within the $X-i, X+i$ values. Figure 5 shows the implied mean average estimated with the RNDs. It can be observed in this figure that the expectations about the exchange rate level (one-month ahead) were increasing before the intervention (extraordinary auction) took place. On average, once the intervention occurred, the agents decrease their expectations about the value of the dollar. In other words, the intervention help to appreciate the Mexican peso at least in expectations (day $X+1$ ). There is a slight increase in the expectations on day $X+2$, however, after that and subsequent days, on average the expectations appear to show a Mexican peso appreciation (days $X+3$ to $X+5)$. Figure 6 presents the average values for the implied standard deviations using the same methodology. It can be observed in Figure 6 that the volatility (implied standard deviation) was increasing the days before the intervention took place. After the intervention occurred the implied volatility decreases meaning that financial agents have lowered their expectations about the exchange rate variations. However, there is a small increase on day $X+3$ but it soon diminishes for day $X+4$. It is important to consider that during an exchange rate crisis there is high uncertainty in the market at that may explain the marginal increase in the implied volatility once the intervention took place. Figure 7 presents the implied skewness. There is a similar pattern as the previous two figures, that is, there is an increase in the expectations (implied skewness) until the day of the intervention. Once the Central Bank intervened the expectations about a Mexican peso depreciation decrease. For a decrease in the implied skewness the interpretation is that the probability of large Mexican peso depreciation is getting smaller compared to a Mexican peso appreciation of the same magnitude. So, again the market participants are decreasing their expectations that the Mexican peso will depreciate more in the near future once the intervention occurred. Finally, Figure 8 shows the implied Kurtosis using the same method. The graph shows qualitatively similar results as the previous

11 The results and details of these tests are available upon the reader's request. 
graphs. That is, there is a decrease in the uncertainty about the future level of the exchange rate once the intervention was conducted by the Mexican Central Bank. This may suggest that Banco de México interventions decreased the exchange rate expectations as well as its volatility. The following econometric tests are applied in order to analyze if there is a causal relationship between the Mexican peso-USD exchange rate expectations and the interventions conducted by the Central Bank of Mexico.

Figure 5 Implied Mean Averages (Extraordinary Auctions occurred on $X=0$ )

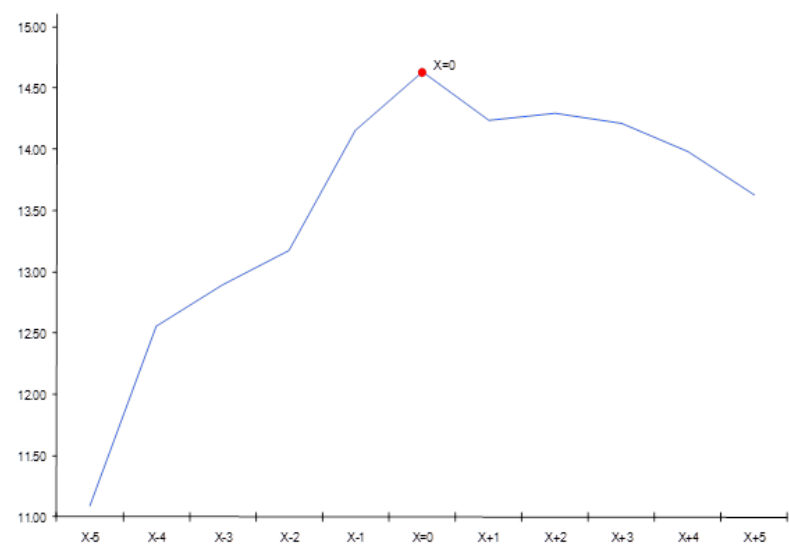

Figure 6. Implied Standard Deviation Averages (Extraordinary Auctions occurred on $\mathrm{X}=0$

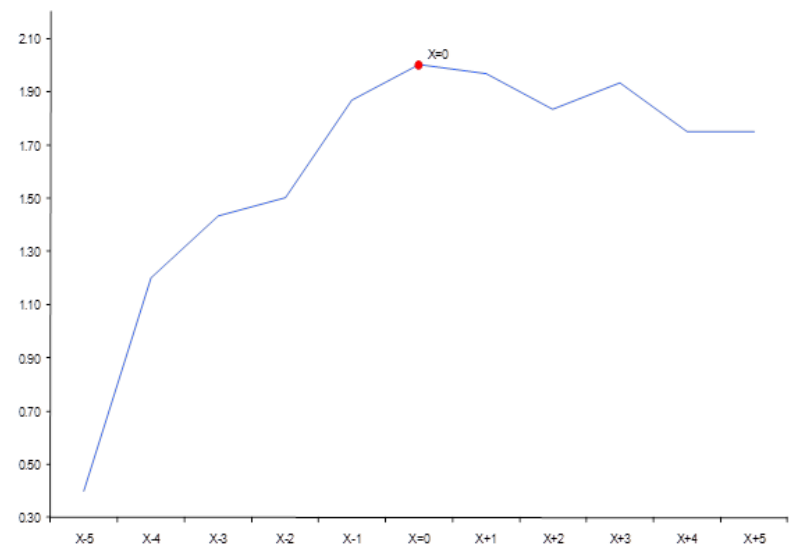


Tabla 7 Implied Skewness Averages (Extraordinary Auctions occurred on $\mathrm{X}=0$ )

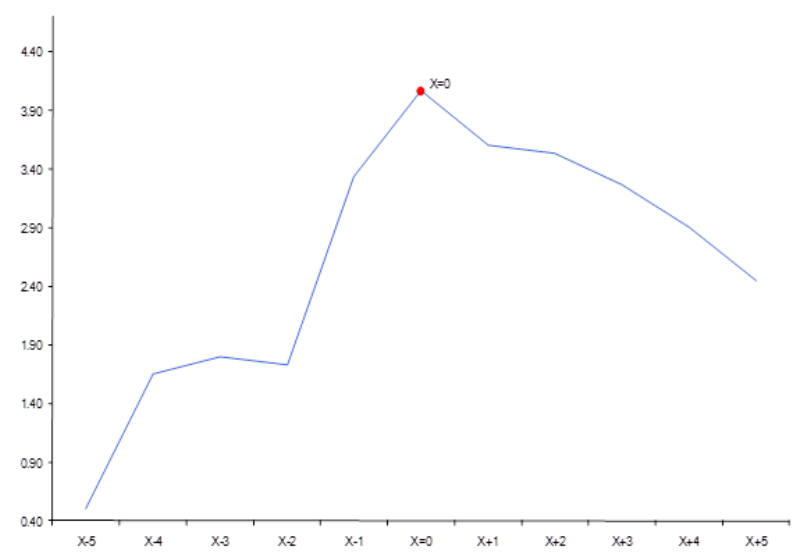

Figure 8 Implied Kurtosis Averages (Extraordinary Auctions occurred on $\mathrm{X}=0$ )

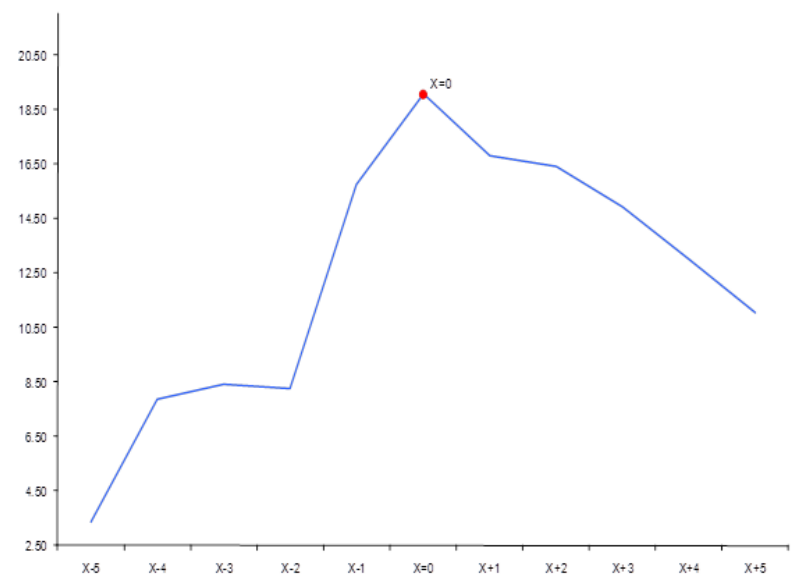

\subsection{Granger-Causality Tests}

The procedure that follows was similarly applied by Galati and Melick (2002). They found that there are statistically significant causal relationships between Central Bank interventions and exchange rate market expectations. These dynamics are important to identify in order to reduce simultaneity bias in structural models. Even though structural models are not postulated in this research paper the following tests still relevant in order to analyze the impact that interventions had on the different moments of the implied distribution i.e. the im- 
plied mean, implied variance and the implied higher moments. ${ }^{12}$ The procedure involves the estimation of the following Granger causality (1969) regression ${ }^{13}$ :

$$
\text { Int }_{t}=\alpha+\sum_{t=1}^{5} \beta_{i} \text { int }_{t-i}+\sum_{t=1}^{5} \phi_{i} M_{t-i}^{j}+\varepsilon_{t}
$$

where $i n t$ represents the intervention (in monetary terms) $M_{t-i}^{j}$ represents the $j$ moment of the implicit distribution. We apply the $F$-statistic to test the null that all the $\phi$ coefficients are jointly zero. If the null is rejected we interpret that the moment causes the intervention.

Two other commonly used causality econometric tests are also applied. One of these was postulated by Sims (1972) that is a modified version of the Granger causality test. The Sims test provides an efficient method for identifying unidirectional causality in a bivariate framework. In this test no causal relation exists if the lag values in Equation 13 below are statistically zero. The other econometric test is the Geweke-Meese-Dent (1983) test. The latter allows for no causal order. Again, all these tests are commonly used in the literature as standard causality tests. The specification for the Sims tests is as follows:

$$
M_{t}^{j}=\alpha+\sum_{t=1}^{5} \beta_{i} i n t_{t-i}+\varepsilon_{t} .
$$

The specification for Geweke-Meese-Dent (GMD) is as follows:

$$
M_{t}^{j}=\alpha+\sum_{t=1}^{5} \beta_{i} i n t_{t-i}+\sum_{t=1}^{5} \phi_{i} M_{t-i}^{j}+\varepsilon_{t} .
$$

For these two last tests the null hypothesis is the same that threre is no causal relationship. So, a rejection of the null hypothesis of no causal relationship implies that there is a relation, in a statistical sense, between the interventions and the moments of the implied distribution (the expectation measures). Table 1 presents the results of all these causality tests. ${ }^{14}$ It can be observed in that Table 1 that the equations for the implied mean and standard deviation has implied coefficients that are statistically significant at the $99 \%$ confidence level

\footnotetext{
12 It is important to point out that Galati and Melick (2002) found few statistically significant relevant parameters in the structural models they used.

13 It is also possible to use a Vector Autoregression model (VAR) with coefficient restrictions to find statistical causality (Granger-causality) in the system of variables. However, in order to be consistent with the literature that uses statistical causality tests, in the present research paper the causality tests are carried out using traditional Granger-causality models, which are useful to test the null hypotheses relevant in this case.

14 These regressions were estimated with White's heteroskedasticity consistent coefficient covariance considering the absence of homoscedasticity in some cases. So, robust standard errors to heteroskedasticity are used.
} 
within a joint coefficient Wald test. ${ }^{15}$ That is, the expectations about the level and volatility of the exchange rate Granger cause the interventions conducted by Banco de México. For the third moment, the implied skewness coefficients are jointly statistically significant at the $90 \%$ confidence level implying that the probability of a large Mexican peso depreciation Granger caused interventions by the Central Bank. Thus, the effect of the expectations, on average, motivated the Central Bank of Mexico to intervene following a significant change of market traders' balance of weights about the Mexican peso depreciation rate. However, for the fourth moment the null hypothesis that the implied kurtosis coefficients were not jointly statistical different from zero cannot be rejected. Thus, there is no evidence that expectations about extreme variations in either direction prompt the Central Bank to intervene.

Table 1. Causality Tests considering Extraordinary Auctions (Interventions) for the Mexican Peso-US Dollar.

\begin{tabular}{ll|ccc}
\hline & Implicit & F-statistic & F-statistic & F-statistic \\
& Moment & Granger test & Sims test & GMD test \\
\hline Intervention & mean & $5.85^{* 8 *}$ & $10.56^{* 88}$ & $5.57^{8 * 8}$ \\
Intervention & Stand. Dev. & $18.46^{* 8 *}$ & $7.19^{* 8 *}$ & $7.93^{* 8 *}$ \\
Intervention & skewness & $1.80^{*}$ & 1.16 & $4.05^{* 8 *}$ \\
Intervention & kurtosis & 0.96 & 0.84 & $3.88^{* 8 *}$ \\
\hline
\end{tabular}

Note: This table presents the estimated coefficients for Equations 12 - 14 presented above. ${ }^{*}=$ significance level at $10 \% .{ }^{* *}=$ significance level at $5 \% .{ }^{* * *}=$ significance level at $1 \%$. These regressions were estimated with White's Heteroskedasticity consistent coefficient covariance considering the absence of homoscedasticity in some cases. So, robust standard errors to heteroskedasticity are used. There is strong statistical evidence that the residuals of these models are i.i.d according to portmanteau tests (Ljung-Box statistics), indicating no serious misspecification errors. The sample period under analysis is $01 / 10 / 08$ through 02/03/09 for a total of 215 daily observations. Stand. Dev. represents standard deviation and GMD denotes Geweke-Meese-Dent test.

The results obtained from the Sims test are qualitatively similar to those for the Granger causality tests. There is a statistical relationship between the expected level (implied mean), expected variation (implied standard deviation) and the interventions. The only difference is that on the Sims test the implied skewness coefficients are jointly equal to zero (again, after applying a Wald test). This can be interpreted as no statistical evidence between the third

\footnotetext{
15 Additionally, it was included as an explanatory variable a lagged exchange rate component in all specifications. The results do not change qualitatively so they are not included here, but they are available upon the reader's request.
} 
implied moment of the distribution and the interventions. There is also no statistical relationship found between implied kurtosis (or expectations about extreme events in either direction) and the interventions. Finally, the GMD tests show that there is statistical significance in all relevant coefficients. That is, all reject the null hypothesis of the lagged coefficients being statistically equal to zero after applying the Wald coefficient restriction test. According to the GMD test the implied moments of the distribution (the exchange rate expectations) are influenced by interventions and past expectations.

The results from the causality tests presented in this section show that overall there is a statistical relationship between the interventions and the expectations about the future exchange rate level (captured by the implied mean) and interventions and the variance of expected future exchange rates (captured by the implied standard deviation). This causality runs in both directions, that is, from interventions to the expectations and vice versa. The results presented here are consistent with that part of the literature that provides evidence that foreign exchange interventions influence exchange rate market expectations. For the case analyzed here it can be concluded that the interventions carried out by the Central Bank of Mexico in October, 2008 had an influence on market participant's exchange rate expectations. However, it cannot be concluded about the effectiveness of those actions. That is because in public announcements from Banco de $\mathrm{M}$ éxico it was not stated the details about the specific objectives reached. Even though there were statistical relationships between the variables of study it is difficult to say that the Central Bank of Mexico reached all its objectives due to data limitations. The effectiveness of such interventions for this empirical study may be a topic for further research.

As a robustness check an intraday volatility analysis is carried out for the 8th October, 2008, that is, the first day of the period of interventions by Banco de México. Figure 9 shows the intraday volatility for that day that is calculated with squared returns for quotes every five minutes i.e. equally distant five-minutes squared returns. The horizontal axis represents Mexico City central time on 08/10/08 and the vertical axis represents the intraday variance for Mexican peso-USD quotes every five minutes. As mentioned in the Data Section above these quotes are taken from Reuters trading platform, which is considered highly representative of Mexican peso-USD intraday transactions.

Considering information that the author obtained by a personal source in Banco de México, the extraordinary auctions by the Central Bank of Mexico occurred at Mexico City central time 11:30 AM (96 million dollars were auctioned), 12:30 pm (2,500 million dollars offered but not bought by market participants) and 1:30 pm (2,500 million dollars offered and 998 million dollars assigned i.e. bought). As it can be observed in Figure 9 there was extreme Mexican Peso-USD volatility before the first intervention of Banco de México, which occurred at 11:30 AM. This can be explained by the fact that New York City time (eastern time US) is one hour ahead Mexico City time (equivalent to central time US) thus, FX traders start trading in the Mexican peso-USD exchange rate once there is exchange rate trading activity in New York. It can be observed in Figure 9 that once Banco de México intervened around 11:30 
AM there is a significant decrease in the intraday volatility. ${ }^{16}$ It appears that the volatility increased again just before the second extraordinary auction of the day (12:30 pm). However, once Banco de México intervened in the Mexican peso-USD exchange rate for the second time that day the volatility decreased significantly and remains relatively low during the rest of the trading day. ${ }^{17}$ So according to these robustness checks there is statistical evidence that interventions by Banco de México influenced the Mexican peso-USD intraday volatility.

Figure 9. Mexican Peso-USD intraday Volatility for $8^{\text {th }}$ October, 2008 considering an Intraday Frequency of 5 minutes (Horizontal Axis Represents

Mexico City Central Time, Vertical Axis shows the Intraday Variance).

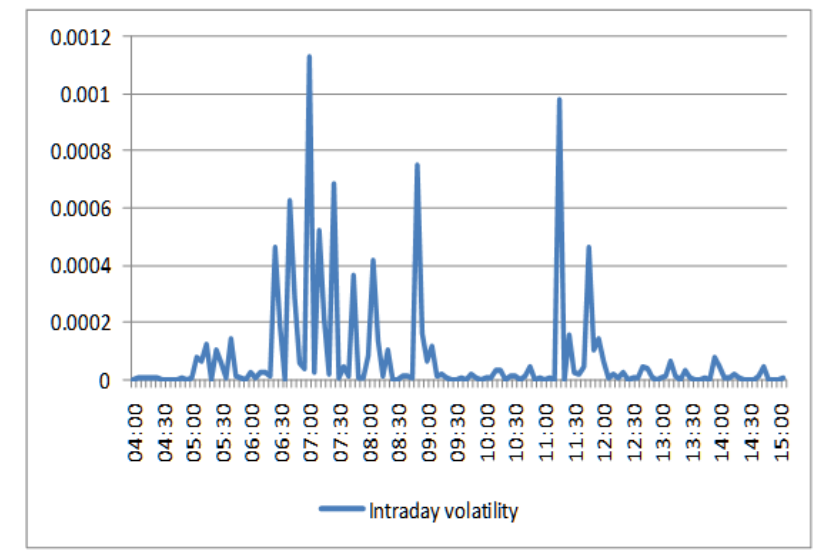

\section{Summary and Conclusions}

In the present research paper an empirical analysis about the interventions conducted by the Central Bank of Mexico during the financial crisis 2008-2009 is carried out. The null hypothesis that Banco de México interventions did not affect agent's expectations about the Mexican peso-USD exchange rate was tested. According to the results presented in this research document it is concluded that the null hypothesis is rejected. Considering the applied econometric tests it is concluded, for the time frame under study that once an intervention (extraordinary auction) takes place by Banco de México expectations about the level and volatility of the exchange rate Mexican peso-USD change. Following an intervention we observe a statistical decrease in both implied mean and implied variance in the Risk-Neutral distributions. A similar qualitatively result is also observed for the higher implied moments, that is, the implied skewness and implied kurtosis also shows a clear statistical decrease. In few words, after

\footnotetext{
16 These decreases in volatility are statistically significant after applying an $F$-test for variance equality. The results do not change qualitatively the main idea presented before so, they are not included here. They are available upon the reader's request.

17 Figure 9 presents trading until 4:00 pm Mexico City time, however, there is no significant change in the Mexican peso-USD volatility after that time for that day.
} 
the exchange rate interventions by Banco de México during the end of 2008 global financial crisis all the implied moments of the Risk-Neutral Densities, on average, (exchange rate expectations) decreased.

In terms of the causality tests presented it was observed bi-causality, that is, the causality runs in both directions between interventions and the implied moments of the distribution. This last point was corroborated by obtaining statistically significant coefficients for those relevant in the Granger-Causality, Sims and Geweke-Meese-Dent equations. The robustness checks for intraday data also hold qualitatively given that it is observed a statistical influence of Banco de México on the Mexican peso-USD. at the specific time of the intervention Exchange rate interventions influenced the intraday volatility for that exchange rate.

These results are important given that nowadays there is no consensus about how central bank foreign exchange interventions influence exchange rate market expectations. In this research paper the objective is limited to measure the reaction of exchange rate expectations once a unilateral intervention in carried out by the Central Bank of Mexico. According to the results there is some evidence of a statistical significant relationship between exchange rate expectations and interventions conducted by Banco de Mexico. These findings contribute to the literature corroborating the existence of these relationships, thus, are in line with that part of the literature that says that there is these statistical relationships. ${ }^{18}$ This could be important to know in several ways. For example, from a perspective of an investor it could be beneficial to have a quantitative measure of the change in exchange rate expectations knowing that there is a foreign exchange intervention taking place. Change in foreign currency expectations surely could change the actual level and variability of the exchange rate, thus, with this measure it could be possible to make betterinformed decisions about portfolio investments. A policy maker could also benefit if it considers this for its policy decisions. The magnitude of the intervention and its influence on the expectations should not be ignored by a policy maker. However, it is difficult to say with these results to what extent this could help to explain monetary policy decisions given that the latter may take into account more variables (or factors) other than the exchange rate level or its volatility. Overall, these results are in line to those found in an earlier study conducted by Galati and Melick (2002) and with that part of the literature that documents that foreign exchange intervention does impact exchange rate expectations. It is important to point out that the present analysis does not consider effectiveness of the exchange rate intervention but only its impact to exchange rate expectations. The effectiveness line of study is left for future research.

\footnotetext{
18 Abarca, Benavides and Rangel (2010) they found a significant statistical relationship between monetary policy announcements (interest rate announcements) and exchange rate market expectations. In the present research document the statistical relationship is evident for the case of central bank exchange rate interventions. Thus, the former finds the statistical relationship once a central bank does a monetary policy announcement, whilst the latter, applies only for exchange rate interventions. It can be said that the present research document corroborates the fact that, central bank action influences exchange rate market expectations.
} 


\section{References}

Abarca, G., Benavides, G. and Rangel, G. (2010). Exchange Rate Market Expectations and Central Bank Policy: The Case of Mexican Peso - US Dollar from 2005 - 2009. Research document published at the Mexican Derivatives Exchange (MexDer) webpage at http://www.mexder.com.mx. This paper was awarded the National Mexican Derivatives 2010 Award and the Financial Markets 2010 Award. Guillermo Ortíz Martínez prize.

Andersen T. G., Bollerslev T., Diebold F. X. and Vega C. (2003). Effects of Macro Announcements: Real-time Price Discovery In Foreign Exchange. The American Economic Review, 93(1) pp. $38-62$.

Bahra, B. (1997). Implied Risk Neutral Probability Density Functions from Options Prices: Theory and Application. Bank of England. Workingpaper No. 66.

Baillie, R. and Osterberg, W. (1997).Why do central banks intervene? Journal of International Money and Finance, 16(6). pp 909-19

Bates, D. S. (1991). The Crash of '87: Was It Expected? The Evidence from Options Markets. Journal of Finance. 46, pp.1009-44. July.

Benavides, G. and Capistrán, C. (2009). Forecasting Exchange Rate Volatility: The Superior Performance of Conditional Combinations of Time Series and Option Implied Forecasts. Banco de México. Documento de investigación No. 2009-01.

Benavides P. G., and Mora F. I. (2008). Parametric vs. Non-Parametric Methods for Estimating Option Implied Risk-Neutral Densities: The Case of the Exchange Rate Mexican Peso - US Dollar. Ensayos. Vol. XXVII, No.1, May. pp. 33-52.

Bliss, R., and N Panigirtzoglou (2000). Testing the Stability of Implied Probability Density Functions. Bank of England. ISSN 1368-5562.

Breeden, D., and R. Litzenberger (1978). Prices of State-Contingent Claims Implicit in Option Prices. it The Journal of Business. 51, pp. 621-51.

Benavides P. G., and F. I. Mora (2008). Parametric vs. Non-Parametric Methods for Estimating Option Implied Risk-Neutral Densities: The Case of the Exchange Rate Mexican Peso - US Dollar. Ensayos. Vol. XXVII, No.1, May. pp. 33-52.

Castrén, O. (2005). Estimating and Analyzing Currency Options Implied Risk-Neutral Density Functions for the Largest New EU Member Status. European Central Bank. Workingpaper No. 440. February.

Christoffersen, P., S. and Mazzotta (2004). The Informational Content of Over-the-Counter Currency Options. European Central Bank. Workingpaper No. 366.

Cooper, N., and J. Talbot (1999). The Yen/Dollar Exchange Rate in 1998: Views from Options Markets. Bank of England. Workingpaper.

Connolly, R. and W. Taylor (1994) . Volume and Intervention Effects of Yen/USD Exchange Rate Volatility, 1977-1979. Advances in Financial Planning and Forecasting. 5. JAI Press. Greenwich, Connecticut.

Deutsche Bundesbank Monthly Report October 2001.

Díaz de León, A., and Casanova, M. E. (2004). Expectativas del Mercado Implícitas en los Precios de Instrumentos Derivados: Aplicaciones al Mercado Cambiario y Petrolero. Banco de Mé xico. Documento de investigación No. 200401.

Dominguez, K. and J. Frankel (1993). Does Foreign Exchange Intervention Work? Institute for International Economics, Washington.

Edison, H. (1993). The effectiveness of Central Bank Intervention: A Survey of the Literature after 1982. Princeton University Special Papers in International Economics No. 18.

Fatum, R. (2000). On the Effectiveness of Sterilized Foreign Exchange Intervention. European Central Bank Working Paper Series. February.

Figlewski, S. (2009). Estimating the Implied Risk-Neutral Density for the U.S. Market Portfolio. Volatility and Time Series Econometrics: Essays in Honor of Robert F. Engle (Eds. Tim Bollerslev, Jeffrey Rusell and Mark Watson). Oxford, UK: Oxford University Press. 
Fleming M. J., and E. M. Remolona (1999). Price Formation and Liquidity in the U.S. Treasury Market: The Response to Public Information. The Journal of Finance, 54(5), pp. $1901-1915$

Galati G., and W. Melick (2002). Central Bank Intervention and Market Expectations. Bank for International Settlements, Monetary and Economic Department, Workingpaper No. 10. April.

Garman, M. B., and S. W. Kohlhagen (1983). Foreign Currency Option Values. Journal of International Money and Finance. 2, pp. 231-37. May.

Geweke, J., R. Meese, and W. Dent (1983). Comparing Alternative Tests of Causality in Temporal Systems: Analytic Results and Experimental Evidence. Journal of Econometrics. 21(2), pp. 161-94.

Granger, C. W. J. (1969). Investigating Causal Relations by Econometric Models and CrossSpectral Methods. Econometrica. 37(3), pp. 424-38.

Liu, X., M. Shackelton, S. Taylor, and X Xinzhong (2007). Closed-form Transformations from Risk-Neutral to Real-world Distributions. Journal of Banking $\mathscr{E}$ Finance, Elsevier, 31(5), pages 1501-1520, May.

Lewis, K. (1988). Testing the Portfolio Balance Model: A Multilateral Approach. Journal of International Economics. 24. pp 109-27. February.

Lyons, R. (2001). The Microstucture Approach to Exchange Rates. MIT Press.

Malz, A. M. (1997). Estimating the Probability Distribution of the Future Exchange Rate from Option Prices. Journal of Derivatives. 5, pp. 18-36.

Mc Manus, D. J. (1999). The Information Content of Interest Rate Futures Options. Bank of Canada. Workingpaper No. 99-15.

Melick, W. R., and C. P. Thomas (1997). Recovering an Asset's Implied PDF from Option Prices: An Application to Crude Oil during the Gulf Crisis. Journal of Financial and Quantitative Analysis. 32, pp. 91-115.

Micu, M. (2004). Extracting Expectations from Currency Option Prices: A Comparison of Methods. Bank of International Settlements. Workingpaper. September.

Neely, C. J. The Practice of Central Bank Intervention: Looking Under the Hood. Federal Reserve Bank of St. Louis. May/June 2001.

Rubinstein, M. (1994). Implied Binomial Trees. Journal of Finance. 49, pp. 771-818. July.

Sims, C. A. (1972). Money, Income and Causality. American Economic Review., 62(4), pp. 540-52.

Taylor, S. J. (2005). Asset Price Dynamics, Volatility, and Prediction. Princeton University Press. 